\title{
URBAN POLICIES AS A SMART GROWTH TOOL TO CONTROL THE ENVIRONMENAL IMPACTS OF TRANSPORTATION
}

\author{
Prof. Dr. Tarek A. Aboul Atta ${ }^{1}$, Marwa M. Talaat Flefal ${ }^{2}$ \\ ${ }^{1}$ Prof. of Urban and Regional Planning, Dept. of Architecture, \\ Faculty of Engineering, Cairo University; ${ }^{2}$ Architect - Supervisor of the GIS Center, \\ Ministry of Antiquities
}

\begin{abstract}
Urban growth has caused many environmental problems, especially urban sprawl leading to the loss of green open spaces and an increase in traffic and energy consumption.

International and domestic climate policy discussions have gravitated toward the goal of limiting the temperature increase to $2^{\circ} \mathrm{C}$ to $3^{\circ} \mathrm{C}$ through cutting greenhouse gas emissions by 60 - 80 percent below 1990 levels by the year 2050 . In view of this massive GHG reduction goals, the transportation sector could play a large role in combating Global Warming. Various policies are proposed to reduce transportation GHG emissions. The success of each of these policies shows in different degrees from one city to another because of the diverse conditions influencing each city.

An analytical statistical study was applied to show the inter-relations between diverse eco-policies and the influencing conditions of cities showing patterns of different behaviors.

In this study, relations between cross cutting indicators affecting the GHG reduction strategies are studied. A sample of policy-Indicators and assessment-indicators will be checked to show that the degree of success differ from one region to another. Inte-relations with other affecting indicators will be discussed as well.

It was clear that, city urban, economic, social, political, and historical background affect the efficiency of applying different eco-policies. The study aims to reach a methodology that can be used as a decision support tool to aid different stakeholders to choose the most efficient eco-policy for a specific city - focusing on cities with higher densities and lower GDP/capita.
\end{abstract}

Keywords: Smart Growth, GHG Reduction Strategies, Transportation GHG, SPSS. 


\section{Introduction:}

It is widely recognized that the Earth's climate is undergoing profound changes. Climate change is proved to be due to external factors and internal factors. External factors include such processes as variations in solar radiation and deviations in the Earth's orbit, while the internal factors can be geological changes like plate tectonics, volcanic activities and the variation in the composition of the atmosphere i.e emission of (GHG). Scientific evidence on climate change and the potential for serious global impact is now stronger than ever [1].

The Intergovernmental Panel on Climate Change (IPCC) states that there is a ninety-percent probability that greenhouse gas emissions produced by human activities have caused most of the observed global warming since the mid-twentieth century [2].

Rising temperatures has already and will continue to occur in response to atmospheric amplified warming. Amplified warming is the result of high concentrations of carbon dioxide emissions and other greenhouse gas emissions (methane, nitrous oxide, halocarbons, and ozone) trapping additional infrared energy beyond what occurs naturally [3].

Therefore, many governments and organizations are seeking measures to reduce emissions. Cities may learn by examining and adapting the strategies of other cities. For such a process to be successful, however, it is necessary for cities to have reliable GHG inventories and to understand how and why their emissions and their responses to environmental policies differ.

The problem:

Literature present a wide range of strategies and policies that can be used to control and limit the impacts of transportation GHG in urban areas; but these strategies have interrelations with each other and with other conditions surrounding each specific set of cities. These interfering relations can impact the effectiveness of these policies and change their main goal in controlling GHG Emissions.

The objective:

The study aims to reach a methodology that can be used as a decision support tool to aid different stakeholders to choose the most efficient eco-policy for a specific city.

The hypothesis:

- The effectiveness of applying a certain eco-policy and its degree of success defer from one city to another. This depends of the specific circumstances of each city.

- Some of the city urban, economic, social, political and environmental conditions affect the efficiency of applying different eco-policies.

- Cities with similar circumstances act the same way in response to environmental governmental policies. 
- Cities' conditions can be used as a tool to predict the efficiency and the degree of success of different environmental policies.

\section{Green House Gases and Climate Change:}

The process of natural warming can be seen in (Figure 1) which is based on the greenhouse effect where the majority of sunlight emitted onto the Earth's surface is absorbed by the oceans and land. The remaining infrared energy radiates outwards from the Earth and is either absorbed by the greenhouse gases, emitted into space, or reflected back toward the Earth's surface [3].

In its Fourth Assessment Report 2007, the IPCC confirmed that the Earth's climate is projected to continue changing in one of six different scenarios. According to these six scenarios, the likely increase in temperature ranges from $1.1^{\circ} \mathrm{C}$ to $6.4^{\circ} \mathrm{C}$ and the likely increase in sea level ranges from 0.18 meters to 0.59 meters. Climate change will have very severe impacts on many people- producing poverty, disease, instability, and death from freak weather events. It will, in particular, have direct consequences for members of developing countries [2].

Figure 1 - The Greenhouse Effect

Source: [4]

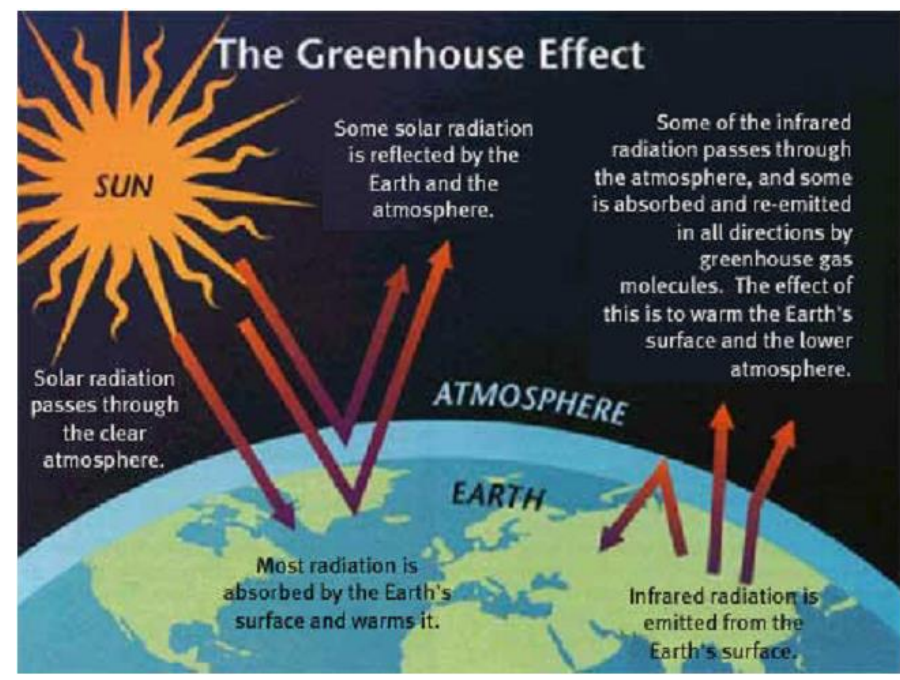

The majority of greenhouse gases are emitted from natural (biogenic) sources, while human activities (anthropogenic sources) generate smaller amounts of greenhouse gases. Powerful natural mechanisms absorb these gases from the atmosphere. Estimates of global emissions are presented in Table 1.

\begin{tabular}{|c|c|c|c|c|}
\hline Gas & $\begin{array}{l}\text { Biogenic } \\
\text { Sources }\end{array}$ & $\begin{array}{l}\text { Anthropogenic } \\
\text { Sources }\end{array}$ & Absorption & $\begin{array}{c}\text { Annual Increase } \\
\text { in Gas in } \\
\text { Atmosphere }\end{array}$ \\
\hline $\mathrm{CO} 2$ (mmtCE) & 150,000 & 7,100 & 154,000 & $3,100-3,500$ \\
\hline CH4 (mmtgas) & $110-210$ & $300-450$ & $460-660$ & $35-40$ \\
\hline $\mathrm{N} 2 \mathrm{O}$ (mmtgas) & $6-12$ & $4-8$ & $13-20$ & $3-5$ \\
\hline
\end{tabular}

Table 1. Global Natural and Anthropogenic Sources and Absorption of Greenhouse Gases

Source: [5] 
According to data presented in table 1 and Figure 2, carbon dioxide is by far the most prevalent greenhouse gas emitted into the atmosphere aside from water vapor. Increasing concentrations of $\mathrm{CO} 2, \mathrm{CH} 4$, and $\mathrm{N} 2 \mathrm{O}$ in the atmosphere indicate that more gases are being emitted than absorbed each year, despite the ability of natural mechanisms to absorb greenhouse gases. Records from the Antarctic ice core reveal that the carbon cycle has been in a state of imbalance for the past 200 years, with emissions of carbon dioxide exceeding absorption capacities. Both naturallyoccurring and human-induced greenhouse gas emissions arise from a variety of processes and activities [6].

The primary human source of $\mathrm{CO} 2$ is the combustion of fossil fuels, which accounts for about two thirds of total anthropogenic emissions of carbon worldwide [6]. Every gallon of gasoline burned produces about 20 pounds of $\mathrm{CO} 2$ emissions [7]. Fossil fuels are consumed for transportation, industrial processes, and residential purposes [6]. See figure 3, 4 .

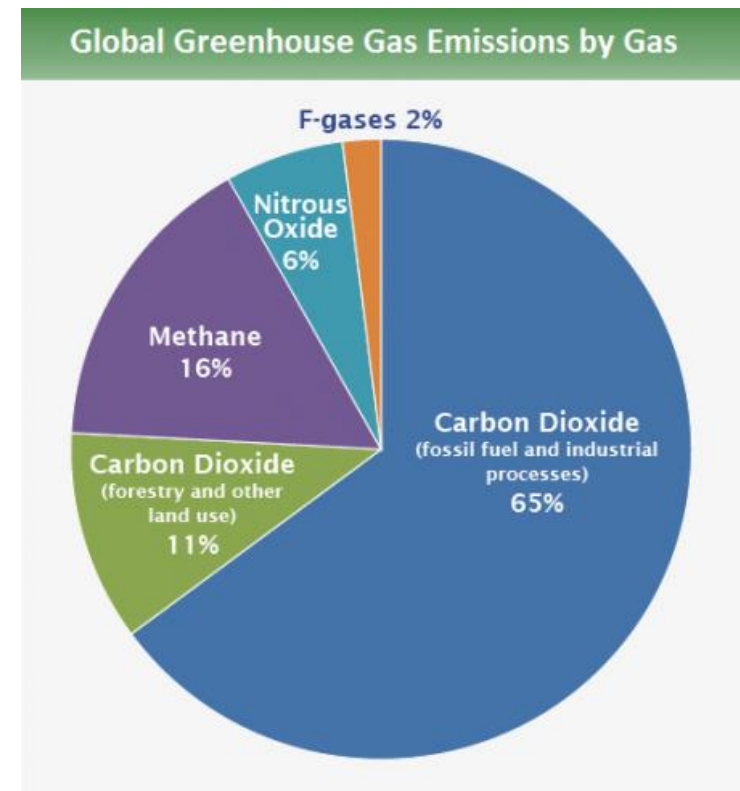

Figure 2

Figure 2: Global GHG Emission by Gas.

Figure 3: Global GHG Emission by Economic Sector.

Figure 4: Global CO2 Emissions from Fossil Fuels, 1900 to 2014.

Source :[8]

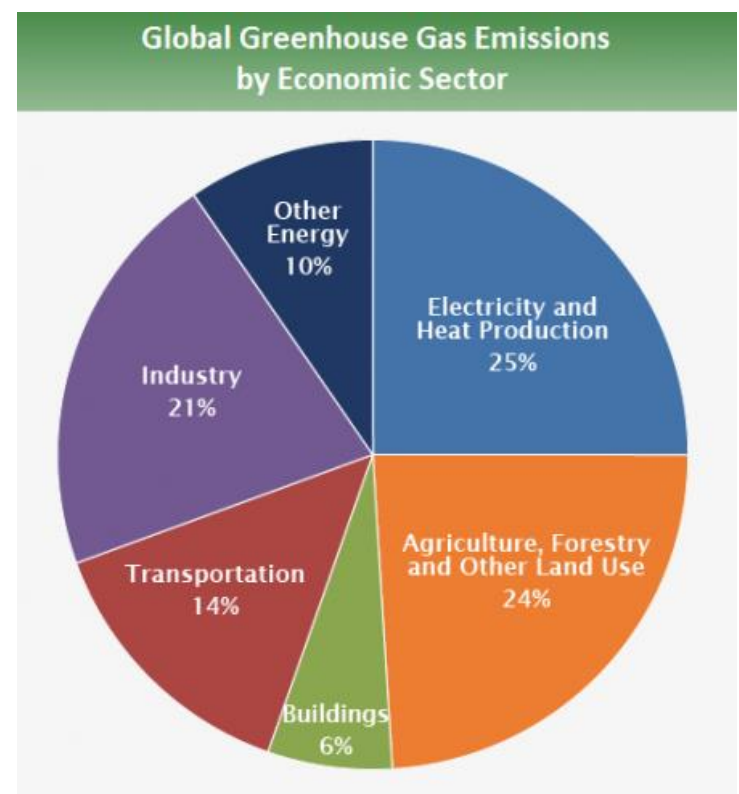

Figure 3

Global Carbon Emissions from Fossil Fuels, 1900-2014

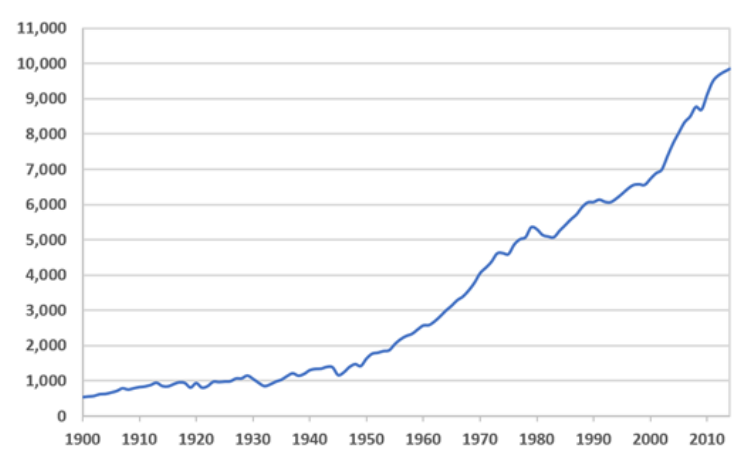

Figure 4 


\section{Travel, Energy Use, and Greenhouse Gas Emissions:}

The study will focus on the transportation GHG that are related to the major activities affected by land use patterns of urban areas. The impacts of land-use patterns on energy and GHG at a site or neighborhood level can be significant. A recent review of the literature concluded that vehicle travel is typically $20 \%$ to $40 \%$ lower for residents of compact neighborhoods compared to residents of sprawl neighborhoods [7]. Infill sites have been shown to reduce VMT by $15 \%$ to $50 \%$ compared to greenfields (previously undeveloped locations) [9]. Data from a VMT forecasting model developed by Polzin and $\mathrm{Chu}$ of the Center for Urban Transportation Research (2007) and based on the 2001 National Household Travel Survey (NHTS) suggests that households in the highest-density neighborhoods (over 10,000 ppsm) produce less than half the annual carbon dioxide (CO2) emissions produced by households in the lowest-density neighborhoods (under 500 ppsm) [10].

The key changes in land development patterns could help reduce vehicle greenhouse gas emissions. Based on a comprehensive review of dozens of studies by leading urban planning researchers, it can be concluded that urban development is both a key contributor to climate change and an essential factor in combating it [11].

\section{Impacts of Urban Form on Emissions:}

Transportation emissions reduction can be viewed as a three-legged stool, with one leg related to vehicle fuel efficiency (such as using hybrid cars), a second to the carbon content of the fuel itself (such as biodiesel fuel), and a third to the amount of driving or vehicle miles traveled (VMT).

As previous researches compiled clear, technological improvement in vehicles and fuels are likely to be offset by continuing, robust growth in VMT. As an example: since 1980, the number of miles Americans drive has grown three times faster than the U.S. population, and almost twice as fast as vehicle registrations (Figure 2) [11].

Figure 5: Growth of VMT, Vehicle Registrations, and Population in the United States relative to 1980 Values.

Source: [11]

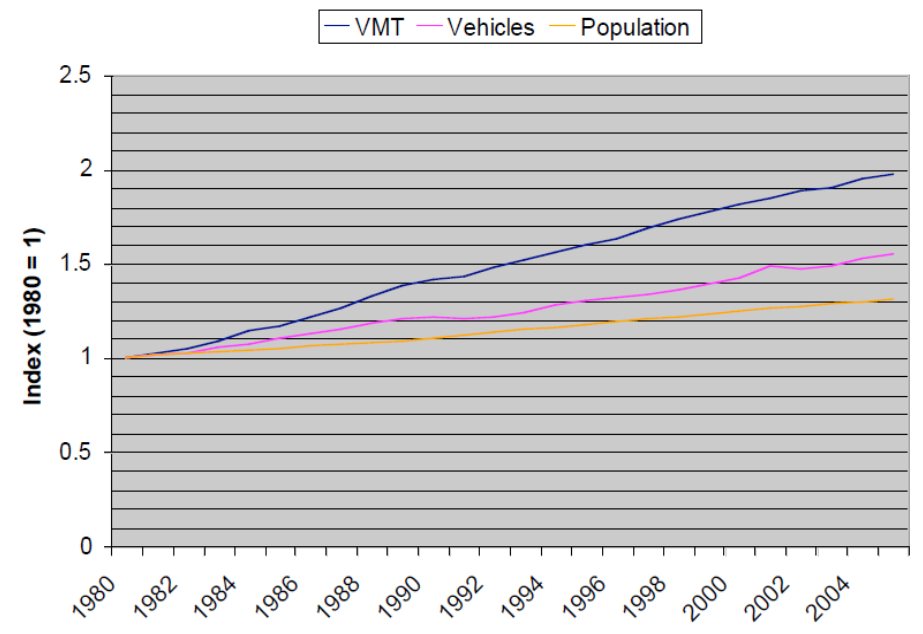

The growth in driving is due in large part to urban development. For more than 60 years, many developed countries have built homes far from workplaces schools and 
other destinations - such as shopping. From World War II until very recently, nearly all new development has been planned and built on the assumption that people will use cars virtually every time they travel. As a result car trips and distances have increased, and walking and public transit use have declined. Population growth has been responsible for only a quarter of the increase in vehicle miles driven over the last couple of decades. A larger share of the increase can be traced to the effects of a changing urban environment, namely to longer trips and people driving alone [11].

The U.S. Department of Energy's “Energy Information Administration" (EIA) forecasts that driving will increase 59 percent between 2005 and 2030, outpacing the projected 23 percent increase in population. The EIA also forecasts a fleetwide fuel economy improvement of 12 percent within this time frame, primarily as a result of new federal fuel economy standards for light trucks. Despite this improvement in efficiency, $\mathrm{CO} 2$ emissions would grow by 41 percent. Other Influences on $\mathrm{CO} 2$ Emissions are Vehicle Trip Frequencies and Vehicle Operating Speeds (45 miles/h is best).

Better community planning and more compact development help people live within walking or bicycling distance of some of the destinations they need to get to every day-work, shops, schools, and parks, as well as transit stops. If they choose to use a car, trips are short. Rather than building single-use subdivisions or office parks, communities can plan mixed-use developments that put housing within reach of these other destinations. The street network can be designed to interconnect, rather than end in culs-de-sac and funnel traffic onto overused arterial roads.

Finally, by building more homes as condominiums, townhouses, or detached houses on smaller lots, and by building offices, stores and other destinations "up" rather than "out," communities can shorten distances between destinations. This makes neighborhood stores more economically viable, allows more frequent and convenient transit service, and helps shorten car trips [11].

\section{Greenhouse Gas Reduction Strategies:}

In light of the aggressive GHG reduction goals, the transportation sector could play a large role in combating Global Warming. Dozens of strategies are proposed to reduce transportation GHG emissions. The strategies are organized into four major groups. They include strategies to: [12]

\section{A. Introduce low-carbon fuels:}

The objective of this group of strategies is to develop and introduce alternative fuels that have lower carbon content and therefore generate fewer transportation GHG emissions. These alternative fuels include ethanol, biodiesel, natural gas, liquefied petroleum gas, low carbon synthetic fuels (such as biomass-to-liquids), hydrogen, and electricity.

\section{B. Increase vehicle fuel efficiency:}

The objective of this group of strategies is to reduce GHG emissions by using less fuel per distant unit traveled. Fuel efficiency improvements include 
advanced engine and transmission designs, lighter weight materials, improved aerodynamics, and reduced rolling resistance.

\section{Improve transportation system efficiency:}

These strategies seek to improve the operation of the transportation system through reduced vehicle travel time, improved traffic flow, decreased idling, and other efficiency of operations; improvements that can also result in lower energy use and GHG emissions. Efficiency can also be improved by shifting travel to more efficient modes, where such shifts are practical in terms of price and convenience - such as passenger vehicle to bus.

\section{Reduce carbon-intensive travel activity:}

The objective of this group of strategies is to influence travelers' activity patterns to shift travel to more efficient modes, increase vehicle occupancy, eliminate the need for some trips, or take other actions that reduce energy use and GHG emissions associated with personal travel.

It is clear that strategies related to the distances traveled and the usage of other modes of transportation is directly related to comprehensive city planning. In the light of this strategies related to improving transportation system efficiency and the reduction of carbon-intensive travel activity will be discussed in more details:

\subsection{List of Strategies to Improve transportation system efficiency: [13]}

\subsubsection{Highway Operations and Management}

Traffic Management - Technologies and practices to reduce congestion and smooth traffic flow through improved traffic operations and management, such as signal coordination, faster clearance of incidents, and freeway ramp metering.

- Real-Time Traveler Information - Provision of up-to-date information to travelers and truckers on traffic conditions, incidents, and expected delays; the availability of public transportation and other travel alternatives; weather conditions; road construction; and special events.

- Bottleneck Relief - Increased capacity at "bottlenecks" (specific points on the transportation network where demand exceeds capacity), such as interchanges, intersections, and lane drops.

- Reduced Speed Limits - Reduced speed limits on high speed facilities, including the InterState system, other limited access highways, and possibly high speed rural major arterials, to no more than 55 or $60 \mathrm{mph}$.

\subsubsection{Truck Operations and Management}

- Truck Idle Reduction - Education, laws, and/or incentives to introduce technology (such as electrical hook-ups at truck stops or on-board auxiliary power supplies) to reduce long-duration idling of heavy vehicles.

- Truck Size and Weight Limits - Changes to Federal law to allow vehicles exceeding 80,000 pounds to operate on InterState highways; and/or to allow longer (53') trailers or double or triple trailers in all States. 
Urban Consolidation Centers - Freight facilities where deliveries (retail, office, or residential) can be consolidated for subsequent delivery into the urban area in an appropriate vehicle with a high level of load utilization.

\subsubsection{Freight Rail, Marine, and Aviation Operations}

Rail and Marine Modal Diversion - Infrastructure improvements to encourage shippers to shift freight traffic to modes that are more energy- and carbonefficient (generally from trucking to rail or marine), through reductions in the time and cost of shipping or increased reliability by these modes; financial incentives or disincentives that encourage different shipping patterns; and other policy and regulatory actions.

- Rail and Intermodal Terminal Operations - Reducing or eliminating chokepoints in the rail intermodal system to eliminate existing rail traffic friction, increase rail throughput potential, decrease variability in travel time, and decrease overall travel time; thus reducing emissions associated with vehicle delay and low-speed operations.

- Ports and Marine Operations - Land-side and marine-side strategies to increase the energy efficiency of operations at ports and reduce GHG emissions, such as reducing truck idling and VMT within the terminal, rail service to inland distribution centers, and shore-side power for ships.

- Aviation Operations - Operational procedures to reduce delays and GHG emissions from aircraft, such as improvements in airport efficiency, direct routing of flights, reduced separation, and continuous descents.

\subsubsection{Infrastructure Construction and Maintenance}

Construction Materials - Use of less energy-intensive construction materials by State and local highway departments and other transportation agencies, such as recycled material in cement and asphalt that is prepared at a lower temperature.

- Other Transportation Agency Activities - Other transportation agency operating practices to reduce GHG emissions, such as alternative fuel fleet and construction vehicles, energy efficient buildings, and work zone management to reduce traffic congestion.

\subsection{List of Strategies to Reduce Carbon-Intensive Travel Activity: [13]}

\subsubsection{Pricing}

- VMT Fees - Charging drivers per mile of travel.

- Intercity Tolls - Applying tolls to rural InterState and other limited-access highways.

- Pay-as-You-Drive Insurance - Converting a significant portion of the essentially fixed cost of insurance to a marginal cost based on mileage.

- Congestion Pricing - Pricing roadway facilities when they are congested in order to reduce traffic on those facilities to an improved level of service.

- Cordon/Area Pricing - Applying a fee for vehicles to enter or operate within a selected area, such as a central business district. 


\subsubsection{Transit, Nonmotorized, and Intermodal Travel}

Transit Expansion, Promotion, Service Improvements - Investing in new fixedguideway urban transit, expanding coverage of bus systems, increasing the frequency and/or time coverage of service on existing routes, or making other improvements to the quality of service on urban transit systems.

- Intercity Bus and Rail - Bus and rail passenger services (improvements to existing Amtrak services, or investment in new high-speed rail corridors) in corridors up to 500 miles between major city pairs.

- Nonmotorized Transport - Capital investments in nonmotorized infrastructure (e.g., bicycle facilities, sidewalks), or supporting activities such as design standards, bicycle parking at destinations, or education programs, to encourage bicycling, walking, and other forms of nonmotorized transport.

- Passenger Intermodal Improvements - Coordinating infrastructure and services to facilitate transfers between modes in order to maximize the efficiency of travel and minimize passengers' time and costs.

\subsubsection{Land Use and Parking}

Land Use - Coordinated regional transportation and land use planning to develop and implement growth policies (e.g., zoning for compact, walkable communities), in conjunction with supportive infrastructure investment, to reduce vehicle-travel.

- Parking Management - Changes to parking supply, pricing, or other management techniques to create disincentives to driving.

\subsubsection{Commute Travel Reduction}

Worksite Trip Reduction Programs - Requirements for employers to reduce single-occupancy vehicle trips by their employees, or outreach, assistance, and incentive programs to encourage them to do so.

- Telework - The practice of working from a location other than the regular workplace and using modern telecommunications and computer technology to bridge the resulting distance.

- Compressed Work Week - A scheduling system whereby a regularly scheduled number of hours are worked in a shortened span of time.

- Flexible Work Schedules - Employer-facilitated alternatives to a standard 9:00 a.m. to 5:00 p.m. work schedule for commuting employees.

- Ridematching, Carpooling, and Vanpooling - Programs such as ridematching databases, vanpooling programs, and other supportive actions to increase vehicle occupancies for work trips.

\subsubsection{Public Information Campaigns}

Information on Travel Choices - Mass marketing and individualized marketing campaigns to provide people with information on the full range of travel options and impacts of their choices. 
Information on Vehicle Purchase - Information directed at influencing consumers' purchasing decisions by providing complete information on the environmental, cost, and other impacts of their purchases.

Driver Education/Eco-Driving - Education programs directed at increasing vehicle fuel efficiency by affecting both driver behavior and vehicle maintenance.

\section{Cross Cutting Strategies and Efficiency Assessment Indicators:}

Out of studying the previous strategies and their roll in GHG reduction a group of cross cutting strategies (Policy Indicators) and efficiency assessment indicators can be deduced:

\subsection{Efforts that cut across these four strategy groups are (Policy Indicators): [12]}

Transportation planning. Discusses transportation planning and investment efforts that offer cross-cutting system efficiency and travel activity strategies. Transportation planning and investment decisions can improve the operating efficiency of the multi-modal transportation network, and integrate transportation and land use planning to reduce travel distances.

Pricing carbon. Discusses pricing carbon through a cap and trade system, carbon tax, or increased motor fuels tax. The objective of this group of strategies is to reflect the broader costs of climate change by increasing the cost of emitting $\mathrm{CO}_{2}$ and thereby influencing consumers and businesses to reduce $\mathrm{CO}_{2}$ emissions. Policies that would price carbon emissions affect all four strategy groups: by increasing the cost of emitting greenhouse gases, they encourage the lowest cost combinations of the use of low carbon fuels, the purchase of energy efficient vehicles, the adoption of efficiency improvements in transportation systems, and the reduction of travel demand.

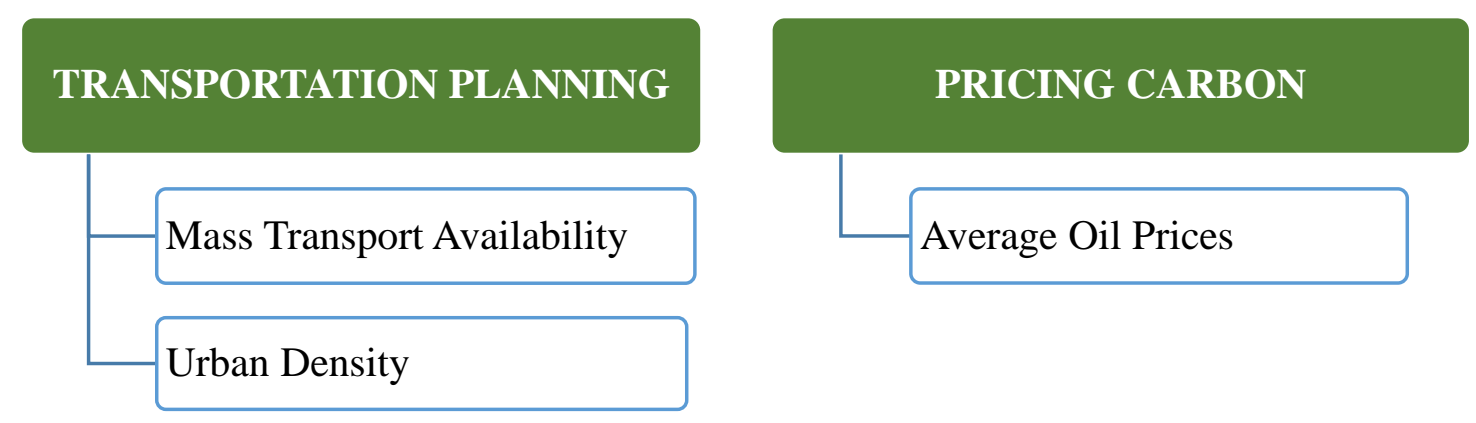

Figure 6: Cross cutting strategies used in the analysis

Source: The researcher

\subsection{Efficiency Assessment Indicators:}

These are the main indicators that can be used to assess the efficiency and success of the used GHG reduction strategies. 


\section{EFFICIENCY ASSESSMENT INDICATORS}

The percent of the residents walking, cycling or taking the public transport to work

Energy usage per capita

Amount of $\mathrm{Co} 2$ per capita emmitted from the energy use

Figure 7: Efficiency Assessment Indicators used in the analysis Source: The researcher

6. Analytical study -the relations between policy-Indicators and Goal-indicators

\subsection{Data Collection:}

Data was collected for 57 cities in Europe and North America for the years (2007 to 2015) from different sources [14, 15, 16, 17, and 18]. Cities chosen have different characteristics and conditions i.e. size, population density, main activity, living standard, location. Cities were chosen in North America and Europe for the following reasons:

- North America and Europe are the main historical producers of the GHG emissions.

- They have more fiscal power that can allow them to apply the agreed recommendations and enforce policies to reach them.

- They have more stable regional and local political systems and an advanced experience in governance.

\subsubsection{Indicators included in the study}

In addition to Policy Indictors and Efficiency assessing Indicators, some of the Indicators deduced from the readings and literature review are included in this paper. These indicators are listed below:

- Environmental performance (score)

- City Population

- Environmental Governance (score)

- City area $(\mathrm{km} 2)$

- Eco-building policies (score)

- Density (head/km2)

- Waste and land use polices (score)

- Coastal status

- Latitude of the city (absolute value)

- Dry lands ecosystem

- Electricity consumption (GJ/capita)

- Energy consumption (GJ/capita)

- GDP (total - PPP - USD)

- Average Petroleum Prices USD/liter

- GDP per capita (PPP - USD)

- Total CO2 emissions from energy production $(\mathrm{kg})$

- $\mathrm{CO} 2$ emissions from energy production per capita (kg/capita)

- Coverage of public and mass transport network $(\mathrm{km} / \mathrm{km} 2)$ 
- $\%$ of workers walking, cycling or taking public transport networks

6.1.2. List of cities:

\begin{tabular}{|c|c|c|c|}
\hline \multicolumn{4}{|c|}{ Europe } \\
\hline \multicolumn{2}{|c|}{ West Europe } & \multicolumn{2}{|c|}{ East Europe } \\
\hline Country & City & Country & City \\
\hline Austria & Vienna & Bulgaria & Sofia \\
\hline Belgium & Brussels & Croatia & Zagreb \\
\hline Denmark & Copenhag & Czech & Prague \\
\hline Finland & Helsinki & Estonia & Tallinn \\
\hline France & Paris & Hungary & Budapest \\
\hline Germany & Berlin & Latvia & Riga \\
\hline Greece & Athens & Lithuania & Vilnius \\
\hline Ireland & Dublin & Poland & Warsaw \\
\hline Italy & Rome & Romania & Bucharest \\
\hline Netherlands & Amsterda & Slovakia & Bratislava \\
\hline Norway & Oslo & Ukraine & Kiev \\
\hline Portugal & Lisbon & Bulgaria & Sofia \\
\hline Serbia & Belgrade & & \\
\hline Slovenia & Ljubljana & & \\
\hline Spain & Madrid & & \\
\hline Sweden & Stockhol & & \\
\hline Switzerland & Zurich & & \\
\hline
\end{tabular}

\begin{tabular}{|c|c|c|c|}
\hline \multicolumn{4}{|c|}{ North America } \\
\hline Country & City & Country & City \\
\hline Canada & Calgary & USA & Miami \\
\hline Canada & Montreal. & USA & Minneapolis \\
\hline Canada & Ottawa & USA & New York \\
\hline Canada & Toronto & USA & Orlando \\
\hline Canada & Vancouver & USA & Philadelphia \\
\hline USA & Atlanta & USA & Phoenix \\
\hline USA & Boston & USA & Pittsburgh \\
\hline USA & Charlotte & USA & Sacramento \\
\hline USA & Chicago & USA & San \\
\hline USA & Cleveland & USA & Seattle \\
\hline USA & Denver & USA & St. Louis \\
\hline USA & Detroit & USA & Washington \\
\hline USA & Houston & & \\
\hline USA & \begin{tabular}{|l} 
Los \\
Angeles
\end{tabular} & & \\
\hline
\end{tabular}

Table 3: North American cities included in the study

Table 2: European cities included in the study

\subsection{Procedure:}

In this study, relations between cross cutting indicators affecting the GHG reduction strategies are studied. A sample of 3 Cross Cutting GHG Reduction Strategies Indicators will be checked with 2 Efficiency Assessment Indicators to show that the degree of success differ from one region to another. Inte-relations with other affecting indicators will be discussed as well.

\section{Cross Cutting GHG Reduction Strategies:}

Urban Density

Public and mass transport network availability

Average Petroleum Fuel Price

\section{Efficiency Assessment Indicators:}

Energy consumption per Capita

$\mathrm{CO} 2$ emissions per capita due to energy consumption

The percent of the residents walking, cycling or taking the public transport

Through the statistical analysis a set of interrelations between these indicators and other urban, governmental, economical, climatological, and environmental 
indicators will be studied; resulting into a set of indicative relations and behavioral responses that can be clustered into different sets. In the light of this a set of the most likely effective GHG reduction strategy can be reached for each set of cities that has similar influencing conditions.

\subsection{Results:}

Through studying the correlations in table 4 (studying 57 cities in both North America and Europe); any of the Cross Cutting GHG Reduction Strategies did not show any strong relation with the Efficiency Assessment Indicators except with the case of Average Petroleum Prices. Although this looks very disappointing since it conflicts with the theoretical study, it has a reasonable cause. The relations will differ when clustering the cities according to location, economical and historical background, showing that groups having different conditions can make totally different relations. 


\begin{tabular}{|c|c|c|c|c|c|}
\hline & & & \multicolumn{3}{|c|}{ Efficiency Assessment Indicators (Goal Indicators) } \\
\hline & & & $\begin{array}{c}\text { Energy } \\
\text { consumption } \\
\text { /Capita }\end{array}$ & $\begin{array}{c}\text { CO2 Emissions } \\
\text { /Capita }\end{array}$ & $\begin{array}{l}\% \text { Using Non- } \\
\text { Private-Car }\end{array}$ \\
\hline \multirow{18}{*}{ 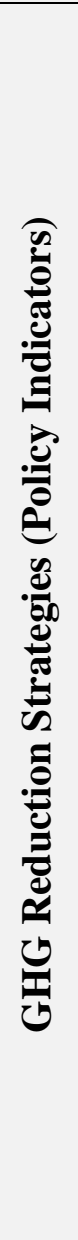 } & \multirow{6}{*}{ 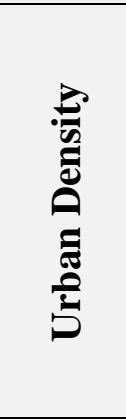 } & All & --- & (-ve) Moderate & (+ve) Moderate \\
\hline & & NA & -- & (-ve) Moderate & (+ve) Strong \\
\hline & & USA & -- & (-ve) Moderate & (+ve) Very strong \\
\hline & & EU & (-ve) Moderate & Weak & Weak \\
\hline & & WEU & (-ve) Very strong & (-ve) Strong & (-ve) Moderate \\
\hline & & EEU & Weak & Weak & (+ve) Moderate \\
\hline & \multirow{6}{*}{ 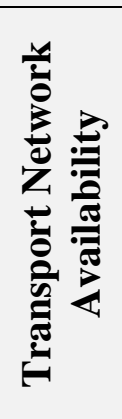 } & All & --- & (-ve) Moderate & (+ve) Moderate \\
\hline & & NA & -- & (-ve) Moderate & (+ve) Strong \\
\hline & & USA & --- & Weak & (+ve) Moderate \\
\hline & & $\mathrm{EU}$ & (-ve) Moderate & Weak & Weak \\
\hline & & WEU & Weak & Weak & (-ve) Moderate \\
\hline & & EEU & (-ve) Strong & (-ve) Moderate & (+ve) Strong \\
\hline & \multirow{6}{*}{ 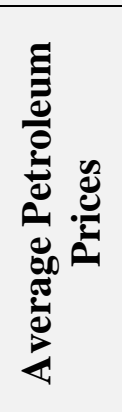 } & All & --- & (-ve) Very strong & (+ve) Very strong \\
\hline & & NA & --- & (-ve) Moderate & (+ve) Strong \\
\hline & & USA & --- & --- & --- \\
\hline & & EU & Weak & (+ve) Moderate & Weak \\
\hline & & WEU & Weak & (+ve) Moderate & Weak \\
\hline & & EEU & Weak & Weak & Weak \\
\hline
\end{tabular}

\begin{tabular}{|c|c|c|c|}
\hline Weak & Moderate & Strong & Very strong \\
\hline$<300$ & 300 to 500 & 500 to 700 & $>700$ \\
\hline
\end{tabular}

\begin{tabular}{|c|c|c|c|}
\hline All & Complete City Sample (57) & EU & European Cities (30) \\
\hline NA & North American Cities (27) & WEU & West European Cities (19) \\
\hline USA & USA Cities (22) & EEU & East European Cities (11) \\
\hline
\end{tabular}

Table 4: European cities included in the study Source: The researcher 


\subsubsection{Urban Density VS. Energy Consumption per capita:}

- Urban Density showed a medium correlation to Energy Consumption per capita in the collective sample, North American cities, and European cities. When clustering European cities into eastern and western cities, the correlation was much stronger in West European cities (-.567* sig 0.11).

- A negative relation appears between density and energy demand; as the density increases, the demand of energy/capita required for transportation decreases.

\subsubsection{Urban Density VS. Using Non-Private-Car Indicator:}

- There is a correlation of moderate strength between Urban Density and nonprivate-car indicator in the analysis of 57 cities (.318* sig.016). The relation was checked in the sample containing only North American cities. It was a much stronger positive relation at $\left(.625^{* *} \mathrm{sig} .000\right)$ while when checked in the sample containing only the European city no correlation appeared (.124 sig .513).

- When clustering European cities to East and West European cities it was clear that the result is totally different. In East European cities the correlation showed a moderate-high positive score at $\left(.466^{*} \mathrm{sig} .149\right)$ while in West European cities the score was (-.437 sig .061).

- Another result is that the percent of people not using personal vehicles in America (average $=13 \%$ ) is really affected by the urban density and compact development while in Western Europe (average $=62 \%$ ) it does not relate with density and other factors may have the most dominant effect.

- Although North American cities and West European cities have similar GDP per capita; they have opposite reaction to the same policy.

- That result shows the huge effect of historical, economic social and political backgrounds of the sample cities on the behavior of its population.

\subsubsection{Public Mass Transport Network Availability VS. Energy Consumption per capita:}

- A moderate negative correlation showed when studying the collective sample of 57 cities (- .314* sig .022). While when clustering cities, North American cities showed a negative medium-high correlation $\left(-.416^{*}\right.$ sig .031$)$ and European cities showed a much weaker correlation (-.285 sig .141) with a significant differences between western and eastern European cities, where Eastern cities showed a medium to high relation to the energy consumption

- A negative relation appears between public mass transport network availability and energy consumption per capita; as the public mass transport network availability increases the energy consumption per capita dcreases

\subsubsection{Public Mass Transport Network Availability VS. Using Non- Private-Car Indicator:}

- A moderate positive relation showed when studying the collective sample $\left(.405^{*}\right.$ sig .003), while in North American cities a stronger high score appeared $\left(.541^{* * *}\right.$ sig .004). 
- On the other hand in European cities the score was very disappointing showing no correlation (.054 sig .783). but again when clustering European cities into eastern and western cities the result is very different:

$\circ$ East European cities showed moderate-high positive score $\left(.505^{*}\right.$ sig .136) meaning that more working citizens walk, use bike or public transit if the network system is available. Encouraging more citizens to use public modes of transportation.

○ West European cities showed moderate negative score $\left(-.345^{*}\right.$ sig .161) meaning that the percentage of working citizens using non private cars decreases while the coverage of mass transit systems increases. Other cultural and economic factors affected this result leading that the usage of non-private car does not depend on public network availability.

- Through studying the relation between the percent of people not using personal vehicles and the GDP/Capita showed no correlation in North American cities while it showed a moderate negative correlation with in Europe $\left(-.422^{*} \operatorname{sig} .020\right)$ which support the difference between eastern and western cities behavior mentioned previously.

\subsubsection{Average Prices of Petroleum Vs. Energy Consumption Per Capita:}

- A strong negative relation appears in the collective sample showing that the increase in petroleum prices leads to the decrease of energy consumption ($\left..678^{* * *} \mathrm{sig} .000\right)$ showing that this policies as a strong tool to control energy consumption and combating GHG emissions.

- In the case of North American cities the correlation shows a moderate negative relation $\left(-.439^{*} \mathrm{sig} .028\right)$. Despite to the nature of the urban areas in north American cities and the need to drive longer distances to reach daily destinations in the sprawling cities with less public transit coverage, the taxing policies showed a significant effect.

\subsubsection{Average Prices of Petroleum Vs. Using Non-Private-Cars:}

- A strong positive relation appears in the collective sample showing that the increase in petroleum prices leads to the increase in using non private cars and depending on both walking and biking $\left(.877^{* *} \operatorname{sig} .000\right)$.

- While in North American cities the analysis shows a less strong positive relation $\left(.656^{* *} \operatorname{sig} .000\right)$. On the other hand European cities again showed no relation ($.081 \mathrm{sig} .684)$.

\subsection{Conclusion:}

Through the preliminary analysis of the data using SPSS, some of the outcomes showed up. They can be summarized as follows:

- Through studying the collective sample of the cities (57 cities) clear relations showed an effective role of the governmental GHG reduction strategies to achieve their main goals. 
- The efficiency of these policies varied when the sample group was clustered onto regional, economical and other historical and cultural basis.

- As the density increases, the demand of energy/capita required for transportation decreases and the percentage of working citizens using non private vehicles increases. Significant results appeared in sprawling cities showing the great effect of changing the urban density.

- Other urban indicators that showed a moderate efficiency is the population of the cities as the population increases the demand for energy consumption per capita decreases.

O On the other hand city area did not have any significant effect on any of the goal indicators.

- Similar results showed when studying the availability of mass transit network; where medium to high efficiency appeared in decreasing the request for energy per capita and increasing the percentage of citizens using public transport mentioned urban policies. Results altered greatly between Western and Eastern European cities, indicating that other cultural and economic factors affected this result leading that the usage of non-private car does not depend on public network availability.

$\circ$ The most controlling tool that showed a very high efficiency in controlling the consumption of energy per capita and increases the percentage of citizens using public transit is fossil fuel taxing.

- Some main guidelines that can aid a decision maker are deduced from the above results:

○ Urban density has the strongest effect in high GPD/capita cities (NA and WEU cities)

- Public Mass Transportation Availability has the strongest effect in cities with higher densities and lower GDP/ capita (Canada vs. USA cities) and (EEU vs. WEU cities)

- Fuel taxing has the strongest effect in low densities sprawling cities even if these cities has a high GDP/capita and in the case of low coverage of Public Mass Transportation Network (NA cities).

- Fuel taxing showed less efficiency in cities with lower GDP/capita where the coverage of Public Mass Transportation Network is higher.

- For cities with higher densities and lower GDP/capita, the most efficient GHG reduction strategy is Fuel taxing but only in the case of:

$\circ$ the presence of a proper coverage of Public Mass Transportation Network; and

- the establishment of a strong cultural background based on the development of the collective awareness of the society. 


\section{References:}

[1] Stern, Nicholas. "STERN REVIEW: The Economics of Climate Change". WORLD ECONOMICS. Vol.7, No.2. April-June 2006. Retrieved 20/4/2016, from: http://www.hmtreasury.gov.uk/d/Summary_of_Conclusions.pdf

[2] IPCC, "Climate Change 2007: The Physical Science Basis. Contribution of Working Group I to the Fourth Assessment Report of the Intergovernmental Panel on Climate Change". Retrieved 20/4/2016, from:

https://www.ipcc.ch/publications_and_data/publications_ipcc_fourth_assessment_r eport_wg1_report_the_physical_science_basis.htm

[3] Staudt, Amanda, Nancy F Huddleston and Ian Kraucunas. "Understanding and Responding to Climate Change: Highlights of National Academies Reports". National Academies, 2008.

[4] Oswald, Michelle. 'Literature Review: Transportation Adaptation in Response to Climate Change." University of Delaware University Transportation Center.

[5] US Department of Energy, Energy Information Administration. "Emissions of Greenhouse Gases in the United States, 1995". Retrieved 2/6/2017, from: https://www.eia.gov

[6] US Energy Information Administration (eia). "Emissions of Greenhouse Gases in the United States 1999". Retrieved 20/4/2016, from:

https://www.eia.gov/environment/emissions/archive/ghg/gg00rpt/index.html

[7] Ewing, Reid and Keith Bartholomew. "Land Use-Transportation Scenario Planning in an Era of Global Climate Change (2008)". TRB 2008 Annual Meeting. Washington DC.

[8] United States Environmental Protection Agency. "Global Greenhouse Gas Emissions Data". Retrieved 20/7/2018, from: https://www.epa.gov/ghgemissions/global-greenhouse-gas-emissions-data

[9] Kooshian, Chuck and Steve Winkelman. "Growing Wealthier Smart Growth, Climate Change and Prosperity". January 2011 Center for Clean Air Policy. Retrieved 20/7/2018, from:

http://growingwealthier.info/docs/growing_wealthier.pdf

[10] Cambridge Systematics. "TRANSPORTATION ENERGY FUTURES SERIES: Effects of the Built Environment on Transportation: Energy Use, Greenhouse Gas Emissions, and Other Factors". U.S. Department of Energy Office of Energy Efficiency and Renewable Energy. March 2013.

[11] Ewing, Reid, Keith Bartholomew, Steve Winkelman, Jerry Walters, Don Chen, Barbara Mccann and David Goldberg. "Growing Cooler: The Evidence on Urban Development and Climate Change." Urban Land Institute (2008).

[12] Cambridge Systematics. "Transportation's Role in Reducing U.S. Greenhouse Gas Emissions: Volume 1". U.S. Department of Transportation (DOT) Center for Climate Change and Environmental Forecasting (2010).

[13] Cambridge Systematics. "Transportation's Role in Reducing U.S. Greenhouse Gas Emissions: Volume 2". U.S. Department of Transportation (DOT) Center for Climate Change and Environmental Forecasting (2010). 
[14] The World Bank. World Development Indicators CD-ROM. World Bank, 2004.

[15] World Health Organization, and UNAIDS. Air quality guidelines: global update 2005. World Health Organization, 2006.

[16] "City Mayors: Mayors running the world's cities." City Mayors: Mayors running the world's cities. Accessed July 8, 2017. http://www.citymayors.com/.

[17] "DEMOGRAPHIA: Demographics Development Impacts Market Research \& Urban Policy." DEMOGRAPHIA: Demographics Development Impacts Market Research \& Urban Policy. 2013. Accessed August 28, 2017. http://www.demographia.com/

[18] Green City Index. The Economist Intelligence Unit, sponsored by Siemens. Accessed June 20, 2017.

https://www.siemens.com/entry/cc/features/greencityindex_international/all/en/pdf/ gci_report_summary.pdf

\section{السياسات الحضرية كأداة نمو ذكية للتحكم في الآثار البيئية

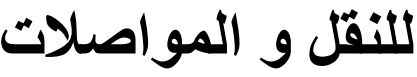

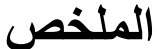
أثرت الأنشطة البشرية منذ عام 1750 على تركيزات ثاني أكسيد الكربون و الميثان و أكسيد النيتروز

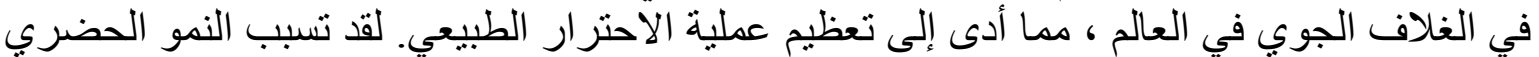

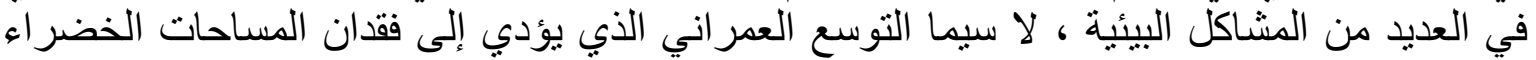
المفتوحة وزيادة في حركة المرور و استهلاكلك الطاقة.

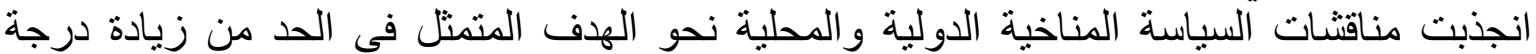

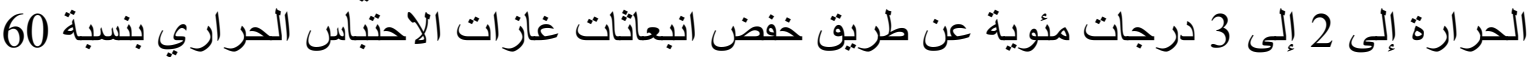

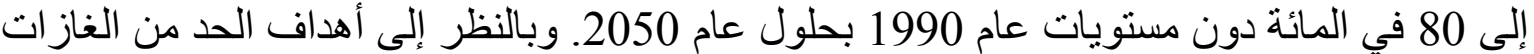
الافيئة هذه، يمكن لقطاع النقل لعب دور كبير في مكافحة ظاهرة الاحتباس الحرارئ العاري.

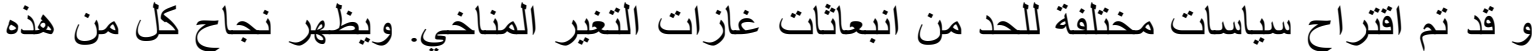

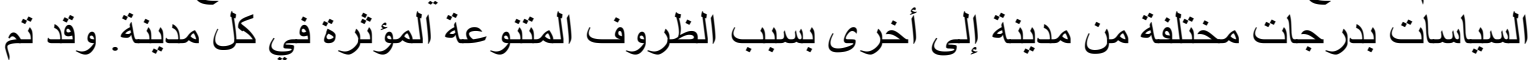

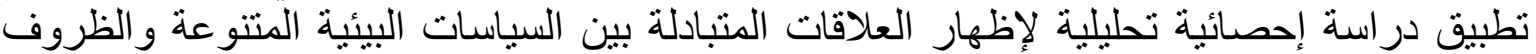
المؤثرة في المدن التي تظهر أنماط استجابة مختلفة الكية.

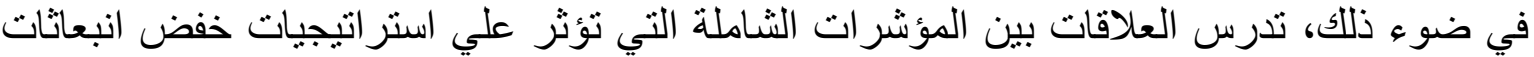

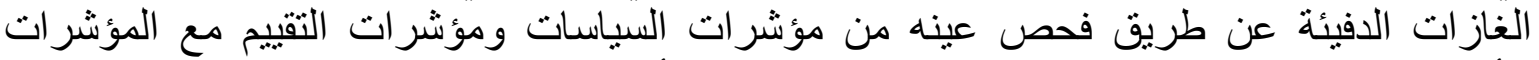

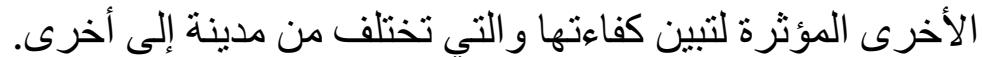

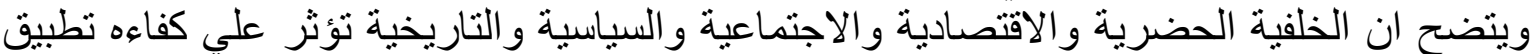

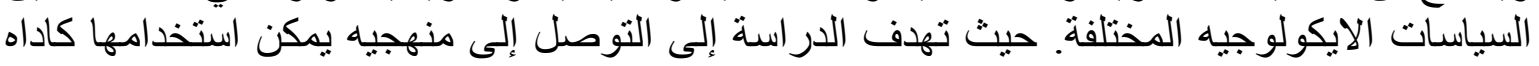

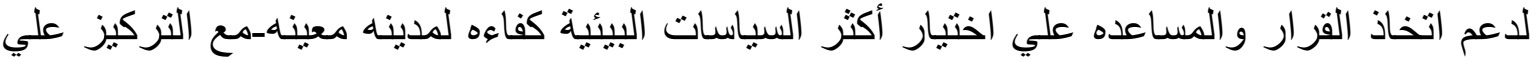
الددن ذات الكثافات العالية و مستوى دخل الفرد المتوسط. 